\title{
Conservação de mamão minimamente processado com uso de revestimento comestível à base de goma xantana
}

\section{Conservation of papaya minimally processed with the use of edible coating based on xanthan gum}

\author{
William Renzo Cortez-Vega ${ }^{1 *}$; Inajara Beatriz Brose Piotrowicz ${ }^{2}$; \\ Carlos Prentice ${ }^{3}$; Caroline Dellinghausen Borges ${ }^{4}$
}

\begin{abstract}
Resumo
Neste trabalho foi avaliada a conservação do mamão "Formosa" minimamente processado, com o uso de revestimento comestível à base de goma xantana, por 12 dias a $4 \pm 1^{\circ} \mathrm{C}$. Foram realizados os tratamentos: controle (T1), sem revestimento; revestimento com $0,5 \%$ de goma xantana (T2); revestimento com $0,5 \%$ de goma xantana e $1 \%$ de quitosana (T3); revestimento com $0,5 \%$ de goma xantana e $0,25 \%$ de goma guar (T4); revestimento com $0,5 \%$ de goma xantana, $0,25 \%$ de goma guar e $1 \%$ de quitosana (T5). Tais revestimentos foram preparados em solução aquosa e adicionados a eles $1 \%$ do plastificante glicerol. No tratamento controle e nos pedaços de mamão revestidos foram analisados a perda de massa, firmeza, $\mathrm{pH}$, acidez titulável cor e os seguintes grupos de micro-organismos: psicrófilos, Salmonella spp., coliformes totais e termotolerantes. Os diferentes revestimentos à base de goma xantana foram eficientes na conservação do mamão "Formosa" minimamente processado, em relação à amostra controle. A adição de goma guar ao revestimento de xantana influenciou negativamente na perda de massa e nos parâmetros de cor, luminosidade, $\mathrm{a}^{*}$ e b*. A adição de quitosana (T3) influenciou beneficamente na redução da perda de massa, manutenção da luminosidade e menor redução nos parâmetros $a^{*}$ e b*, entretanto, não foi observado efeito antimicrobiano. Assim, sugere-se como revestimento comestível de mamão "Formosa" minimamente processado o revestimento composto somente de goma xantana (T2), o qual propiciou redução da perda de massa, manutenção da luminosidade e b* e menor redução no $\mathrm{a}^{*}$. Entretanto, experimentos visando à manutenção da firmeza, $\mathrm{pH}$ e acidez deverão ser futuramente realizados.
\end{abstract}

Palavras-chave: Análise microbiológica, Carica papaya, cor, goma guar, perda de massa, quitosana, textura

\begin{abstract}
The objective of this study was to evaluate the preservation of papaya minimally processed by the use of edible coatings based on xanthan gum for 12 days at $4 \pm 1{ }^{\circ} \mathrm{C}$. Different treatments were performed: control (T1) uncoated; $1 \%$ glycerol and $0.5 \%$ xanthan gum (T2); $1 \%$ glycerol, $0.5 \%$ xanthan gum and $1 \%$ chitosan (T3); $1 \%$ glycerol, $0.5 \%$ xanthan gum and $0.25 \%$ guar gum (T4); $1 \%$ glycerol, $0.5 \%$ xanthan gum, $0.25 \%$ guar gum and $1 \%$ chitosan (T5). Such coatings were prepared in aqueous solution and added to them $1 \%$ glycerol. In the control treatment and the coated pieces of papaya were analyzed weight loss, firmness, $\mathrm{pH}$, titratable acidity, color, and microbiological groups: psychrophilic, Salmonella spp., total coliform and thermotolerant. The different coatings based on xanthan gum were
\end{abstract}

Prof. da Universidade Federal da Grande Dourados, UFGD, Dourados, MS. E-mail: williamvega@ufgd.edu.br

Discente da Universidade Federal do Rio Grande, FURG, Rio Grande, RS. E-mail: inabbp@yahoo.com.br

Prof. da FURG, Rio Grande, RS. E-mail:dqmprent@furg.br

${ }^{4}$ Prof ${ }^{a}$ da Universidade Federal de Pelotas, UFPeL, Pelotas, RS. E-mail: caroldellin@bol.com.br

Autor para correspondência 
effective in preserving papaya minimally processed, relative to control sample. The addition of guar gum to xanthan coatings influenced negatively in the weight loss and the parameters of color, lightness, $a^{*}$ and $b^{*}$. The addition of chitosan (T3) beneficially influence in reducing weight loss, maintenance of luminosity and a smaller reduction in parameters $\mathrm{a}^{*}$ and $\mathrm{b}^{*}$, however, was not observed antimicrobial effect. Thus, it is suggested as an edible coatings papaya minimally processed coatings composed only xanthan gum (T2), which caused a reduction of weight loss, maintenance of lightness and $\mathrm{b}^{*}$ and smaller reduction in $\mathrm{a}^{*}$. However, experiments aimed at maintaining firmness, $\mathrm{pH}$ and acidity should be conducted in future.

Key words: Carica papaya, xanthan gum, guar gum, chitosan, microbiological analysis, physicochemical analysis

\section{Introdução}

A produção brasileira de mamão está baseada nos grupos "Formosa" e "Havaí". O mamão "Formosa" é destinado, principalmente, para o mercado interno, enquanto o "Havaí" para os mercados externo e interno (ROCHA et al., 2005). Esta fruta tem polpa delicada e saborosa e suas características sensoriais (textura, cor e aroma), químicas (baixa acidez e bom equilíbrio entre açúcares e ácidos orgânicos) e digestivas, a torna um alimento ideal e saudável para pessoas de todas as idades. De maneira geral, ela é consumida in natura, mas sua industrialização permite o aproveitamento integral e a oferta de extensa gama de produtos e subprodutos, que podem ser usados pelas indústrias de alimentos, farmacêuticas e de ração para animais (HINOJOSA; MONTGOMERY, 1988).

A tendência de mudanças nos hábitos alimentares da população mundial mostra um aumento discreto no consumo de frutas e hortaliças. Entretanto, temse verificado a busca por alimentos com maior conveniência, ou seja, aqueles que exigem tempo reduzido de manuseio e preparo e mantem suas características sensoriais e nutricionais originais (SILVA et al., 2009). Neste sentido, a procura por produtos minimamente processados, tem aumentado. Estes são definidos como produtos vegetais que passaram por alterações físicas, isto é, foram descascados, picados, torneados ou ralados, dentre outros processos, mas mantidos no estado fresco e metabolicamente ativos (MORETTI, 2007).

Os maiores consumidores desse tipo de produto estão nos supermercados, hotéis, restaurantes, fast- foods, por atenderem principalmente pessoas que desejam praticidade e aquelas que dispõem de pouco tempo para preparar seus alimentos (TEIXEIRA et al., 2001). O mamão "Formosa" é um exemplo de produto, cujo consumo é muitas vezes limitado pelo tamanho e a inconveniência do descascamento, fazendo com que a forma minimamente processada amplie a sua comercialização, pois permite o consumo nas mais diferentes ocasiões, e sua utilização nos diferentes serviços de alimentação (SOUZA; DURIGAN, 2007).

Dentre os maiores problemas relacionados ao mamão minimamente processado podem-se citar a perda de água por evaporação e exsudação, que promovem a dessecação superficial dos tecidos, assim como a mudança de coloração e a perda de firmeza decorrentes das modificações na estrutura e na composição da parede celular, pela ação de enzimas como as pectinases, celulases, $\beta$-galactosidase e glicosidases (CHITARRA, 1999; SOUZA; DURIGAN, 2007). Existem algumas maneiras de contornar esses problemas, tais como: utilização de embalagem PET (GODOY et al., 2003), armazenamento a baixas temperaturas de 3 a $6{ }^{\circ} \mathrm{C}$ (SOUZA et al., 2005; OLIVEIRA JUNIOR et al., 2007), adição de cloreto de cálcio para controlar a perda de firmeza (PEIXOTO et al., 2008). Além destes, tem-se também o uso de revestimentos comestíveis, definidos como uma fina camada de material comestível, depositada na superfície de um alimento. Sua finalidade é inibir ou reduzir a difusão de umidade, de oxigênio, de dióxido de carbono e de aromas, pois promovem barreiras semipermeáveis (KROCHTA; MULDER-JOHNSTON, 1997). 
Revestimentos comestíveis podem ser preparados a partir de proteínas, polissacarídeos, lipídeos ou a combinação desses componentes (CAO; FU; HE, 2007). Em mamão inteiro ou minimamente processados tem sido utilizados como revestimentos, principalmente, agentes gelificantes como fécula de mandioca, alginato, gelana, amido de arroz (PEREIRA et al., 2006; TAPIA et al., 2008; BESINELA JUNIOR et al., 2010; TRIGO et al., 2012) e ainda agente espessante, carboximetilcelulose (BESINELA JUNIOR et al., 2010; TRIGO et al., 2012) e agente antimicrobiano quitosana (BESINELA JUNIOR et al., 2010).

A goma xantana é um polissacarídeo produzido por espécies de bactérias do gênero Xanthomonas, normalmente, Xanthomonas campestris pv campestris. É solúvel em água fria ou quente e apresenta estabilidade em relação à variação de temperatura, $\mathrm{pH}$ e força iônica. Esta goma tem sido utilizada em diversos produtos, como agente espessante e estabilizante (GARCÍA-OCHOA et al., 2000).

A goma guar é extraída do endosperma da semente de Cyamopsis tetragonolobus. É solúvel em água fria e a viscosidade é pouco afetada pelo $\mathrm{pH}$ e por sais, entretanto grandes quantidades de açúcar podem reduzir sua viscosidade. É também utilizada como agente espessante e estabilizante. Altas viscosidades são encontradas quando em sinergismo com a goma xantana (RIBEIRO; SERAVALLI, 2007).

A quitosana é um polímero natural derivado do processo de desacetilação da quitina. É uma substância que tem sido empregada em filmes antimicrobianos por apresentar ação bactericida e fungicida (SOARES; GERALDINE, 2007).

As combinações de goma xantana com goma guar, classificados como agentes espessantes, e ainda quitosana, classificado como um agente antimicrobiano pode ser uma alternativa de revestimento comestível de mamão "Formosa" minimamente processado, visto que o sinergismo destes diferentes polissacarídeos é desconhecido. Deste modo, o objetivo do presente trabalho foi avaliar a conservação do mamão "Formosa" minimamente processado pelo uso de revestimentos comestíveis à base de goma xantana.

\section{Materiais e Métodos}

\section{Material}

Foram utilizadas unidades de mamão "Formosa" adquiridas no comércio local da cidade de Rio Grande/RS. As frutas foram selecionadas quanto a massa média de, aproximadamente, $2,0 \mathrm{~kg}$, formato alongado, cor, estando no estádio de maturação nível 3, com $50 \%$ a $75 \%$ da casca amarela, sem defeitos fisiológicos e infecções detectáveis, como indicado por Lima et al. (2005).

As amostras foram transportadas em caixas de isopor até o Laboratório de Tecnologia de Alimentos da Escola de Química e Alimentos da Universidade Federal de Rio Grande, onde foram armazenadas a $4 \pm 1^{\circ} \mathrm{C}$ durante 12 horas, até a realização do processamento.

\section{Preparo das amostras}

O processamento foi realizado em sala com temperatura de, aproximadamente, $10^{\circ} \mathrm{C}$, usandose utensílios previamente higienizados com a solução de cloro orgânico (dicloroisocianurato), na concentração de 2 g.L $L^{-1}$. Os mamões também foram higienizados com a solução de cloro orgânico a 2 g.L-1 , por 10 minutos. A matériaprima foi submetida à remoção manual da casca e sementes, sendo cortada, manualmente, em pedaços de aproximadamente 2,5 x 2,5 cm. Em seguida, os pedaços foram enxaguados com água clorada $(0,2$ g. $\left.\mathrm{L}^{-1}\right)$ para eliminar o suco celular extravasado. A água foi drenada por 2 a 3 minutos sobre peneiras.

No revestimento foram utilizados goma xantana (marca Shandong Fufeng, China), goma guar (marca Sarda Gums \& Chemicals, Índia), quitosana (grau de 
desacetilação em torno de 89 \%, e massa molecular entre 150 e 170 kDa, produzida pela Fundação Universidade de Rio Grande, Brasil) e glicerol (marca Quimex, Brasil). Foram realizados diferentes tratamentos: controle (T1), sem revestimento; (T2) 1 $\%$ de glicerol e $0,5 \%$ de goma xantana; (T3) $1 \%$ de glicerol, $0,5 \%$ de goma xantana e $1 \%$ de quitosana; (T4) $1 \%$ de glicerol, $0,5 \%$ de goma xantana e $0,25 \%$ de goma guar; (T5) $1 \%$ de glicerol, $0,5 \%$ de goma xantana, $0,25 \%$ de goma guar e $1 \%$ de quitosana. Os revestimentos utilizados nos pedaços de mamão foram preparados em solução aquosa. O glicerol, por ser considerado um plastificante, se liga às moléculas do biopolímero, aumentando a mobilidade e diminuindo a densidade entre as suas moléculas, facilitando a transmissão dos gases através do material (MALI; GROSSMANN; YAMASHITA, 2010).

As soluções foram preparadas por dissolução lenta das gomas em água destilada, sob agitação, até completa dissolução, seguindo de aquecimento a $60{ }^{\circ} \mathrm{C}$, por 20 minutos, e resfriamento até a temperatura ambiente, para após serem adicionadas do plastificante glicerol. Os pedaços de mamão foram totalmente submersos nas soluções por 1 minuto e, em seguida, drenados, utilizando-se peneiras sob ventilação até a secagem. Por fim, as amostras revestidas foram acondicionadas em embalagens de 15,5 x 13,2 x 5,5 cm de polietileno tereftalato (PET) com tampa (SANPACK, Brasil). O número de pedaços por embalagem foi padronizado e as embalagens foram armazenadas em condições refrigeradas, a $4 \pm 1{ }^{\circ} \mathrm{C}$. Na análise de perda de massa foi utilizada, de cada grupo de tratamento, três embalagens com perfurações inferiores para que o líquido proveniente da exsudação fosse eliminado durante o armazenamento. As análises físicas, físico-químicas (AOAC, 2000) e microbiológica (APHA, 2001) foram realizadas em triplicata, a cada 2 dias, durante os 12 dias de armazenamento. $\mathrm{O}$ delineamento experimental utilizado foi inteiramente ao acaso em esquema fatorial $5 \times 7$, sendo 5 tratamentos (controle $\mathrm{T} 1$ e os revestimentos T2, T3, T4 e T5) e 7 períodos de avaliação $(0,1,3$, 5, 7, 9 e 12 dias de armazenamento refrigerado).

Análises físicas, fisico-químicas e microbiológicas

Perda de massa

A perda de massa foi obtida relacionandose a diferença entre a massa inicial do mamão minimamente processado e a massa obtida ao final de cada tempo de armazenamento, de acordo com a fórmula: Perda de massa $=[$ (massa inicial - massa final)/(massa inicial)] x 100 . Os resultados foram expressos em porcentagem de perda de massa.

Firmeza

As medidas de firmeza dos cubos de mamão foram determinadas utilizando-se um texturômetro (Stable Micro Systems, modelo TA.XT.plus, Inglaterra), fazendo-se uma compressão com ponteira cilíndrica (0,5 cm de diâmetro) movimentada na velocidade de $4 \mathrm{~mm} \cdot \mathrm{s}^{-1}$ no pré-teste, $8 \mathrm{~mm} \cdot \mathrm{s}^{-1}$ no pós-teste, e $2 \mathrm{~mm} . \mathrm{s}^{-1}$ de teste, até a profundidade de $5 \mathrm{~mm}$. Os resultados foram expressos em Newton $(\mathrm{N})$.

Cor

A cor foi avaliada utilizando-se um colorímetro Minolta, modelo Chroma Meter CR400 (Japão) e detecção dos parâmetros: luminosidade, L*, de 0 (preto) a 100 (branco); a* que varia de verde (-60) a vermelho $(+60)$ e b* de azul $(-60)$ a amarelo $(+60)$ (MINOLTA, 1994).

\section{pH}

$\mathrm{O}$ pH foi determinado em suspensão de $20 \mathrm{~g}$ de amostra em $100 \mathrm{~mL}$ de água destilada, para isto utilizou-se um potenciômetro Marconi modelo PA 200 (Brasil) (AOAC, 2000). 


\section{Acidez titulável}

A acidez titulável foi determinada titulando-se $10 \mathrm{~mL}$ de amostra homogeneizada com $100 \mathrm{~mL}$ de água destilada, usando-se $\mathrm{NaOH}$ 0,1 mol.L ${ }^{-1}$. Os resultados foram expressos em porcentagem de ácido cítrico (AOAC, 2000).

\section{Análises microbiológicas}

Realizou-se testes para a detecção de psicrófilos, coliformes totais, coliformes termotolerantes e Salmonella spp., seguindo-se a metodologia recomendada pela APHA (2001).

\section{Análise dos resultados}

Os resultados obtidos com as avaliações físicas e químicas foram submetidos à comparação de médias pelo Teste de Tukey (5\%), utilizando-se o programa Statistica 6.0 (STATSOFT, 2001).

\section{Resultados e Discussão}

\section{Perda de massa}

Na Tabela 1 estão presentes os resultados médios da perda de massa das amostras de mamão "Formosa" recobertos com os distintos revestimentos ao longo de 12 dias de armazenamento a $4 \pm 1{ }^{\circ} \mathrm{C}$.

Tabela 1. Perda de massa (\%) de amostras de mamão "Formosa" minimamente processado, tratadas com diferentes revestimentos, armazenadas a $4 \pm 1^{\circ} \mathrm{C}$, por 12 dias.

\begin{tabular}{cccccccc}
\hline \multirow{2}{*}{ Tratamentos } & \multicolumn{7}{c}{ Tempo de armazenamento (dia) } \\
\cline { 2 - 7 } & 0 & 1 & 3 & 5 & 7 & 9 & 12 \\
\hline T1 & $0^{\mathrm{a}, \mathrm{G}}$ & $6,85^{\mathrm{a}, \mathrm{F}}$ & $8,49^{\mathrm{a}, \mathrm{E}}$ & $10,50^{\mathrm{a}, \mathrm{D}}$ & $11,92^{\mathrm{a}, \mathrm{C}}$ & $13,22^{\mathrm{a}, \mathrm{B}}$ & $14,95^{\mathrm{a}, \mathrm{A}}$ \\
T2 & $0^{\mathrm{a}, \mathrm{G}}$ & $0,43^{\mathrm{d}, \mathrm{F}}$ & $1,30^{\mathrm{d}, \mathrm{E}}$ & $2,31^{\mathrm{e}, \mathrm{D}}$ & $3,29^{\mathrm{d}, \mathrm{C}}$ & $3,98^{\mathrm{c}, \mathrm{B}}$ & $6,03^{\mathrm{c}, \mathrm{A}}$ \\
T3 & $0^{\mathrm{a}, \mathrm{G}}$ & $0,41^{\mathrm{d}, \mathrm{F}}$ & $1,23^{\mathrm{e}, \mathrm{E}}$ & $2,53^{\mathrm{d}, \mathrm{D}}$ & $3,11^{\mathrm{e}, \mathrm{C}}$ & $3,68^{\mathrm{d}, \mathrm{B}}$ & $5,30^{\mathrm{d}, \mathrm{A}}$ \\
T4 & $0^{\mathrm{a}, \mathrm{G}}$ & $1,01^{\mathrm{b}, \mathrm{F}}$ & $1,59^{\mathrm{c}, \mathrm{E}}$ & $2,98^{\mathrm{b}, \mathrm{D}}$ & $3,66^{\mathrm{c}, \mathrm{C}}$ & $5,03^{\mathrm{b}, \mathrm{B}}$ & $6,07^{\mathrm{c}, \mathrm{A}}$ \\
T5 & $0^{\mathrm{a}, \mathrm{G}}$ & $0,74^{\mathrm{c}, \mathrm{F}}$ & $1,78^{\mathrm{b}, \mathrm{E}}$ & $2,70^{\mathrm{c}, \mathrm{D}}$ & $3,87^{\mathrm{b}, \mathrm{C}}$ & $5,09^{\mathrm{b}, \mathrm{B}}$ & $6,57^{\mathrm{b}, \mathrm{A}}$ \\
\hline
\end{tabular}

Médias seguidas de mesma letra minúscula na coluna e maiúscula na linha não diferem entre si, pelo Teste de Tukey (P<0,05). (T1) Controle; (T2) glicerol $1 \%$ e goma xantana $0,5 \%$; (T3) glicerol $1 \%$, goma xantana $0,5 \%$ e quitosana $1 \%$; (T4) glicerol $1 \%$, goma xantana $0,5 \%$ e guar $0,25 \%$; (T5) glicerol $1 \%$, goma xantana $0,5 \%$, guar $0,25 \%$ e quitosana $1 \%$.

Fonte: Elaboração dos autores.

Houve aumento na perda de massa durante o armazenamento, entretanto as amostras de mamão revestidas apresentaram perda significativamente inferior em relação à amostra T1. As amostras submetidas ao tratamento T2 e T3 apresentaram as menores perdas, 6,03 e 5,30\%, respectivamente. Enquanto as submetidas ao tratamento T5, obtiveram perda de $6,57 \%$, maior perda entre as amostras revestidas. Esperava-se que este tratamento obtivesse a menor perda, devido a maior concentração de polissacarídeos.

$\mathrm{Na}$ amostra T1 a perda foi significativamente superior chegando a $15 \%$ no final do armazenamento, verificando-se assim, que a perda de água e a decomposição natural do fruto foram evitadas pelo efeito barreira exercidas pela combinação dos revestimentos utilizados. Os filmes e coberturas possuem a função de inibir ou reduzir a migração de umidade, oxigênio, dióxido de carbono, lipídios, aromas, dentre outros, pois promovem barreiras semipermeáveis (VICENTINO; FLORIANO; DRAGUNSKI, 2011).

Esta redução na perda de massa é devido à presença do revestimento, que atua como agente sacrificante, ou seja, a desidratação do revestimento ocorre antes do produto revestido (KESTER; FENNEMA, 1986; KROCHTA; MULDERJOHNSTON, 1997). 
Teixeira et al. (2001) avaliaram a perda de massa de amostras de mamão "Formosa" minimamente processados sem uso de revestimento com polissacarídeos, armazenados em embalagem PET, em diferentes temperaturas, por 7 dias. As amostras perderam em média 7,92\%, 7,29\% e $8,15 \%$ da massa inicial quando armazenados a $3^{\circ} \mathrm{C}, 6^{\circ} \mathrm{C}$ e $9^{\circ} \mathrm{C}$, respectivamente. Estes resultados são superiores aos encontrados neste trabalho, em que os pedaços foram revestidos e armazenados a $4{ }^{\circ} \mathrm{C}$. Neste caso se pode evidenciar a eficiência dos polissacarídeos na redução da perda de massa. Entretanto, o valor obtido na amostra controle pelos autores foi inferior ao encontrado neste estudo.

\section{Firmeza}

A firmeza das amostras de mamão "Formosa" minimamente processadas foi influenciada pelo tempo de armazenamento. Através da Tabela 2 pode-se observar que a firmeza dos mamões no tempo zero não diferiu significativamente entre os tratamentos, sendo que, ao final de 12 dias de armazenamento a $4^{\circ} \mathrm{C}$, diminuiu significativamente. Isto pode ser devido à hidrólise dos ácidos pécticos da parede celular ocasionada pela ação das enzimas pectinases, celulase, $\beta$-galactosidase e glicosidases (CHITARRA, 1999; SOUZA; DURIGAN, 2007). Aparentemente, os valores de firmeza também foram influenciados pela perda de massa, visto que a maior perda de massa proporcionou maior firmeza da polpa do mamão, e vice-versa. Segundo Souza et al. (2005) a perda de umidade promove a formação de um tecido superficial resistente, fazendo com que os pedaços tornem-se mais firmes.

As amostras submetidas ao tratamento $\mathrm{T} 1$ apresentaram maiores valores ao término do armazenamento $(9,49 \mathrm{~N})$. Dentre as revestidas, o tratamento T5 apresentou os maiores valores $(7,86$ $\mathrm{N})$ e, as submetidas ao tratamento T3, os menores $(5,56 \mathrm{~N})$.

Tabela 2. Firmeza $(\mathrm{N})$ das amostras de mamão "Formosa" minimamente processado, tratadas com uso de diferentes revestimentos, armazenadas a $4 \pm 1^{\circ} \mathrm{C}$, por 12 dias.

\begin{tabular}{|c|c|c|c|c|c|c|c|}
\hline \multirow{2}{*}{ Tratamento } & \multicolumn{7}{|c|}{ Tempo de armazenamento (dia) } \\
\hline & 0 & 1 & 3 & 5 & 7 & 9 & 12 \\
\hline T1 & $30,27^{\mathrm{a}, \mathrm{A}}$ & $30,27^{\mathrm{a}, \mathrm{A}}$ & $28,21^{\mathrm{a}, \mathrm{B}}$ & $20,76^{\mathrm{a}, \mathrm{C}}$ & $15,98^{\mathrm{a}, \mathrm{D}}$ & $11,55^{\mathrm{a}, \mathrm{E}}$ & $9,49^{\mathrm{a}, \mathrm{F}}$ \\
\hline $\mathrm{T} 2$ & $30,32^{\mathrm{a}, \mathrm{A}}$ & $30,32^{\mathrm{b}, \mathrm{A}}$ & $19,09^{\mathrm{b}, \mathrm{B}}$ & $17,03^{\mathrm{b}, \mathrm{C}}$ & $11,7^{\mathrm{c}, \mathrm{D}}$ & $7,00^{\mathrm{c}, \mathrm{E}}$ & $6,07^{\mathrm{d}, \mathrm{F}}$ \\
\hline $\mathrm{T} 3$ & $31,25^{\mathrm{a}, \mathrm{A}}$ & $31,25^{\mathrm{b}, \mathrm{A}}$ & $17,65^{\mathrm{c}, \mathrm{B}}$ & $17,62^{\mathrm{b}, \mathrm{B}}$ & $14,08^{\mathrm{b}, \mathrm{C}}$ & $7,16^{\mathrm{c}, \mathrm{D}}$ & $5,56^{\mathrm{e}, \mathrm{E}}$ \\
\hline $\mathrm{T} 4$ & $30,32^{\mathrm{a}, \mathrm{A}}$ & $30,32^{b, A}$ & $17,38^{\mathrm{c}, \mathrm{B}}$ & $14,70^{\mathrm{d}, \mathrm{C}}$ & $10,97 \mathrm{~d}, \mathrm{D}$ & 8,61 b,E & $6,55^{\mathrm{c}, \mathrm{F}}$ \\
\hline T5 & $31,15^{\mathrm{a}, \mathrm{A}}$ & $31,15^{\mathrm{b}, \mathrm{A}}$ & $19,98^{\mathrm{b}, \mathrm{B}}$ & $15,60^{\mathrm{c}, \mathrm{C}}$ & $13,51^{\mathrm{b}, \mathrm{D}}$ & $11,99^{\mathrm{a}, \mathrm{E}}$ & $7,86^{\mathrm{b}, \mathrm{F}}$ \\
\hline
\end{tabular}

Médias seguidas de mesma letra minúscula na coluna e maiúscula na linha não diferem entre si, pelo Teste de Tukey (P<0,05). (T1) Controle; (T2) glicerol $1 \%$ e goma xantana $0,5 \%$; (T3) glicerol $1 \%$, goma xantana $0,5 \%$ e quitosana $1 \%$; (T4) glicerol $1 \%$, goma xantana $0,5 \%$ e guar $0,25 \%$; (T5) glicerol $1 \%$, goma xantana $0,5 \%$, guar $0,25 \%$ e quitosana $1 \%$.

Fonte: Elaboração dos autores.

Comportamento diferenciado foi observado por Tapia et al. (2008). Estes autores avaliaram a firmeza de amostras de mamão minimamente processado revestidos com goma gelana e alginato, adicionadas de $\mathrm{CaCl}_{2}$. Segundo os autores, as amostras revestidas apresentaram maior firmeza que a amostra controle. Entretanto, tal fato foi explicado devido a presença do agente de firmeza, $\mathrm{CaCl}_{2}$, adicionado aos revestimentos.

Já no estudo realizado por Trigo et al. (2012) com revestimento de mamão minimamente processado com o uso de amido de arroz, alginato de sódio ou carboximetilcelulose, as médias de firmeza se mostraram variáveis com o tempo de estocagem. Ao 
$15^{\circ}$ dia de armazenamento a amostra revestida com carboximetilcelulose proporcionou maior firmeza da polpa $(6,1 \mathrm{~N})$, seguida da amostra controle $(4,1$ $\mathrm{N})$ e daquelas revestidas com alginato de sódio (2,9 $\mathrm{N})$ e amido de $\operatorname{arroz}(2,7 \mathrm{~N})$.

\section{Cor}

A luminosidade das amostras de mamão recobertas aumentou até o terceiro dia de armazenamento, após este período observou-se redução da luminosidade em todos os tratamentos (Tabela 3). Entretanto, este aumento inicial na luminosidade não foi observado no tratamento T1, cujos valores decresceram no decorrer dos dias, apresentando o maior escurecimento em relação às amostras revestidas. De acordo com Cereda et al. (1995), os revestimentos à base de polissacarídeos são brilhantes e transparentes, melhorando o aspecto visual dos frutos.
Os resultados mostram que as amostras submetidas ao tratamento $\mathrm{T} 3$ obtiveram luminosidade final semelhante a inicial, o que parece estar associado à ausência da goma guar no revestimento, que, por sua vez, conferiu maior opacidade às amostras T4 e T5. A solução de goma guar apresentou coloração semelhante à das gomas xantana e quitosana, entretanto tal diferença nos resultados pode estar relacionada à diferente composição química das gomas. Sugere-se que a presença da galactose na estrutura da goma guar seja a responsável por tal fenômeno. Entretanto, outros autores já mencionaram que a goma guar aumenta a opacidade de filmes e geis sem mencionar tal afirmação (RAO et al., 2010; BEM; POLESI; SARMENTO, 2011).

Tabela 3. Luminosidade $\left(L^{*}\right)$ das amostras de mamão Formosa minimamente processado, tratadas com uso de diferentes revestimentos, armazenadas a $4 \pm 1^{\circ} \mathrm{C}$, por 12 dias

\begin{tabular}{cccccccc}
\hline \multirow{2}{*}{ Tratamento } & \multicolumn{7}{c}{ Tempo de armazenamento (dia) } \\
\cline { 2 - 7 } & 0 & 1 & 3 & 5 & 7 & 9 & 12 \\
\hline T1 & $40,21^{\mathrm{a}, \mathrm{A}}$ & $40,21^{\mathrm{a}, \mathrm{A}}$ & $39,98^{\mathrm{c}, \mathrm{A}, \mathrm{B}}$ & $38,06^{\mathrm{a}, \mathrm{B}, \mathrm{C}}$ & $36,51^{\mathrm{b}, \mathrm{C}, \mathrm{D}}$ & $35,47^{\mathrm{b}, \mathrm{D}, \mathrm{E}}$ & $34,38^{\mathrm{b}, \mathrm{E}}$ \\
T2 & $35,40^{\mathrm{c}, \mathrm{D}}$ & $35,40^{\mathrm{c}, \mathrm{D}}$ & $44,42^{\mathrm{a}, \mathrm{A}}$ & $38,49^{\mathrm{a}, \mathrm{C}}$ & $41,33^{\mathrm{a}, \mathrm{B}}$ & $34,87^{\mathrm{b}, \mathrm{D}}$ & $36,02^{\mathrm{a}, \mathrm{b}, \mathrm{D}}$ \\
T3 & $37,53^{\mathrm{b}, \mathrm{B}}$ & $37,53^{\mathrm{b}, \mathrm{B}}$ & $43,77^{\mathrm{a}, \mathrm{b}, \mathrm{A}}$ & $35,29^{\mathrm{b}, \mathrm{C}}$ & $36,96^{\mathrm{b}, \mathrm{B}, \mathrm{C}}$ & $37,51^{\mathrm{a}, \mathrm{B}}$ & $36,20^{\mathrm{a}, \mathrm{B}, \mathrm{C}}$ \\
T4 & $40,23^{\mathrm{a}, \mathrm{A}}$ & $40,23^{\mathrm{a}, \mathrm{A}}$ & $41,92^{\mathrm{b}, \mathrm{c}, \mathrm{A}}$ & $35,35^{\mathrm{b}, \mathrm{B}}$ & $36,67^{\mathrm{b}, \mathrm{B}}$ & $36,44^{\mathrm{a}, \mathrm{b}, \mathrm{B}}$ & $34,94^{\mathrm{a}, \mathrm{b}, \mathrm{B}}$ \\
T5 & $39,77^{\mathrm{a}, \mathrm{B}}$ & $39,77^{\mathrm{a}, \mathrm{B}}$ & $42,24^{\mathrm{a}, \mathrm{b}, \mathrm{A}}$ & $36,79^{\mathrm{a}, \mathrm{b}, \mathrm{C}, \mathrm{D}}$ & $37,82^{\mathrm{b}, \mathrm{B}, \mathrm{C}}$ & $35,70^{\mathrm{b}, \mathrm{D}}$ & $34,62^{\mathrm{a}, \mathrm{b}, \mathrm{E}}$ \\
\hline
\end{tabular}

Médias seguidas de mesma letra minúscula na coluna e maiúscula na linha não diferem entre si, pelo Teste de Tukey (P<0,05). (T1) Controle; (T2) glicerol $1 \%$ e goma xantana $0,5 \%$; (T3) glicerol $1 \%$, goma xantana $0,5 \%$ e quitosana $1 \%$; (T4) glicerol $1 \%$, goma xantana $0,5 \%$ e guar $0,25 \%$; (T5) glicerol $1 \%$, goma xantana $0,5 \%$, guar $0,25 \%$ e quitosana $1 \%$.

Fonte: Elaboração dos autores.

Comportamento distinto foi observado por Trigo et al. (2012) em que tanto a luminosidade da amostra controle, quanto das revestidas com amido de arroz, alginato de sódio e carboximetilcelulose tenderam à elevação em quinze dias de armazenamento.

Os valores dos parâmetros a* e b* aumentaram significativamente até $o$ terceiro dia de armazenamento para as amostras de mamão, seguido de redução com o tempo de armazenamento (Tabelas 4 e 5). Entretanto, este aumento no parâmetro $a^{*}$ não foi verificado na amostra T1, que seguiu o decréscimo nos valores com o decorrer do armazenamento.

Ao comparar o primeiro e último dia de armazenamento, a menor redução nos valores do parâmetro $a^{*}$ e $b^{*}$ foram obtidos utilizando os 
revestimentos dos tratamentos $\mathrm{T} 2$ e T3. Assim como nos valores de luminosidade, este efeito parece ser influenciado pela ausência da goma guar. A redução nos valores dos parâmetros luminosidade, a* e b* pode estar relacionada a oxidação dos carotenoides pela presença do oxigênio e luz. Desta forma, os tratamentos $\mathrm{T} 2$ e $\mathrm{T} 3$ teriam exercido uma barreira superior ao oxigênio em relação aos demais, provavelmente, devido a maior viscosidade das soluções, já que nestes tratamentos também se pode observar menor perda de massa.

Tabela 4. Parâmetro a* das amostras de mamão Formosa minimamente processadas, tratadas com uso de diferentes revestimentos, armazenadas a $4 \pm 1^{\circ} \mathrm{C}$, por 12 dias.

\begin{tabular}{cccccccc}
\hline \multirow{2}{*}{ Tratamento } & \multicolumn{7}{c}{ Tempo de armazenamento (dia) } \\
\cline { 2 - 7 } & 0 & 1 & 3 & 5 & 7 & 9 & 12 \\
\hline T1 & $26,34^{\mathrm{a}, \mathrm{A}}$ & $26,33^{\mathrm{a}, \mathrm{A}}$ & $25,10^{\mathrm{b}, \mathrm{c}, \mathrm{A}}$ & $21,42^{\mathrm{a}, \mathrm{B}, \mathrm{C}}$ & $20,85^{\mathrm{a}, \mathrm{C}}$ & $13,61^{\mathrm{c}, \mathrm{D}}$ & $12,35^{\mathrm{b}, \mathrm{E}}$ \\
T2 & $20,42^{\mathrm{c}, \mathrm{C}, \mathrm{D}}$ & $20,42^{\mathrm{c}, \mathrm{C}, \mathrm{D}}$ & $27,80^{\mathrm{a}, \mathrm{A}}$ & $21,82^{\mathrm{a}, \mathrm{B}, \mathrm{C}}$ & $19,88^{\mathrm{a}, \mathrm{D}}$ & $17,14^{\mathrm{a}, \mathrm{E}}$ & $12,09^{\mathrm{b}, \mathrm{F}}$ \\
T3 & $19,58^{\mathrm{c}, \mathrm{B}}$ & $19,58^{\mathrm{c}, \mathrm{B}}$ & $28,23^{\mathrm{a}, \mathrm{A}}$ & $14,97^{\mathrm{d}, \mathrm{D}}$ & $17,97^{\mathrm{b}, \mathrm{C}}$ & $14,67^{\mathrm{b}, \mathrm{D}}$ & $12,35^{\mathrm{b}, \mathrm{E}}$ \\
T4 & $23,38^{\mathrm{b}, \mathrm{B}}$ & $23,38^{\mathrm{b}, \mathrm{B}}$ & $26,32^{\mathrm{b}, \mathrm{A}}$ & $18,68^{\mathrm{b}, \mathrm{C}}$ & $18,07^{\mathrm{b}, \mathrm{C}}$ & $11,77^{\mathrm{d}, \mathrm{E}}$ & $13,41^{\mathrm{a}, \mathrm{D}}$ \\
T5 & $18,26^{\mathrm{d}, \mathrm{B}}$ & $18,26^{\mathrm{d}, \mathrm{B}}$ & $23,93^{\mathrm{c}, \mathrm{A}}$ & $17,59^{\mathrm{c}, \mathrm{B}, \mathrm{C}}$ & $17,91^{\mathrm{b}, \mathrm{B}, \mathrm{C}}$ & $13,76^{\mathrm{c}, \mathrm{D}}$ & $9,73^{\mathrm{c}, \mathrm{E}}$ \\
\hline
\end{tabular}

Médias seguidas de mesma letra minúscula na coluna e maiúscula na linha não diferem entre si, pelo Teste de Tukey (P<0,05). (T1) Controle; (T2) glicerol $1 \%$ e goma xantana $0,5 \%$; (T3) glicerol $1 \%$, goma xantana $0,5 \%$ e quitosana $1 \%$; (T4) glicerol $1 \%$, goma xantana $0,5 \%$ e guar $0,25 \%$; (T5) glicerol $1 \%$, goma xantana $0,5 \%$, guar $0,25 \%$ e quitosana $1 \%$.

Fonte: Elaboração dos autores.

Tabela 5. Parâmetro $b^{*}$ das amostras de mamão Formosa minimamente processado, tratadas com uso de diferentes revestimentos, armazenadas a $4 \pm 1^{\circ} \mathrm{C}$, por 12 dias.

\begin{tabular}{cccccccc}
\hline \multirow{2}{*}{ Tratamento } & \multicolumn{7}{c}{ Tempo de armazenamento (dia) } \\
\cline { 2 - 7 } & 0 & 1 & 3 & 5 & 7 & 9 & 12 \\
\hline T1 & $22,35^{\mathrm{a}, \mathrm{C}}$ & $22,35^{\mathrm{a}, \mathrm{C}}$ & $37,60^{\mathrm{a}, \mathrm{A}}$ & $25,12^{\mathrm{a}, \mathrm{B}}$ & $24,43^{\mathrm{b}, \mathrm{B}}$ & $17,78^{\mathrm{d}, \mathrm{E}}$ & $19,49^{\mathrm{a}, \mathrm{D}}$ \\
$\mathrm{T}^{\mathrm{a}}$ & $17,17^{\mathrm{d}, \mathrm{D}}$ & $17,17^{\mathrm{d}, \mathrm{D}}$ & $37,36^{\mathrm{a}, \mathrm{b}, \mathrm{A}}$ & $26,02^{\mathrm{a}, \mathrm{B}}$ & $27,07^{\mathrm{a}, \mathrm{B}}$ & $19,46^{\mathrm{c}, \mathrm{C}}$ & $17,98^{\mathrm{b}, \mathrm{D}}$ \\
T3 & $19,19^{\mathrm{c}, \mathrm{D}}$ & $19,19^{\mathrm{c}, \mathrm{D}}$ & $35,63^{\mathrm{b}, \mathrm{c}, \mathrm{A}}$ & $20,49^{\mathrm{d}, \mathrm{C}}$ & $20,28^{\mathrm{d}, \mathrm{C}}$ & $23,53^{\mathrm{a}, \mathrm{B}}$ & $20,27^{\mathrm{a}, \mathrm{C}}$ \\
T4 & $21,22^{\mathrm{b}, \mathrm{C}}$ & $21,22^{\mathrm{b}, \mathrm{C}}$ & $33,90^{\mathrm{c}, \mathrm{d}, \mathrm{A}}$ & $23,68^{\mathrm{b}, \mathrm{B}}$ & $23,11^{\mathrm{c}, \mathrm{b}, \mathrm{B}}$ & $17,88^{\mathrm{d}, \mathrm{E}}$ & $19,23^{\mathrm{a}, \mathrm{D}}$ \\
T5 & $19,93^{\mathrm{c}, \mathrm{D}}$ & $19,93^{\mathrm{c}, \mathrm{D}}$ & $33,34^{\mathrm{d}, \mathrm{A}}$ & $22,11^{\mathrm{c}, \mathrm{C}}$ & $23,65^{\mathrm{b}, \mathrm{B}}$ & $21,33^{\mathrm{b}, \mathrm{C}}$ & $15,35^{\mathrm{c}, \mathrm{E}}$ \\
\hline
\end{tabular}

Médias seguidas de mesma letra minúscula na coluna e maiúscula na linha não diferem entre si, pelo Teste de Tukey (P<0,05). (T1) Controle; (T2) glicerol $1 \%$ e goma xantana $0,5 \%$; (T3) glicerol $1 \%$, goma xantana $0,5 \%$ e quitosana $1 \%$; (T4) glicerol $1 \%$, goma xantana $0,5 \%$ e guar $0,25 \%$; (T5) glicerol $1 \%$, goma xantana $0,5 \%$, guar $0,25 \%$ e quitosana $1 \%$.

Fonte: Elaboração dos autores.

De acordo com Besinela Junior et al. (2010), a redução do teor de licopeno em mamão minimamente processado está relacionada, principalmente, à sua oxidação pelo oxigênio. Neste trabalho, o revestimento de carboximetilcelulose não foi uma eficiente barreira ao oxigênio propiciando a degradação deste carotenoide.

\section{pH e acidez titulável}

Pode-se observar que o aumento da acidez, com consequente redução do $\mathrm{pH}$, foi independente da aplicação dos revestimentos (Tabelas 6 e 7). Estas variações estão associadas à produção de ácidos orgânicos, como ácido málico e cítrico, decorrente das reações fisiológicas e bioquímicas (LIMA et al., 2005). Além destes, Sarzi et al. (2002a) atribuíram o aumento nos teores de acidez titulável de mamões 
cortados em pedaços, ao aumento no teor de ácido galacturônico em decorrência da atividade enzimática.

Godoy et al. (2003) também observaram que o pH de amostras de mamão minimamente processados armazenados sob refrigeração, por 9 dias, diminuiu de 5,57 para 4,83, enquanto a acidez titulável aumentou de $0,05 \%$ para $0,10 \%$, valores semelhantes aos obtidos neste trabalho.

Tabela 6. $\mathrm{pH}$ das amostras de mamão "Formosa" minimamente processado, tratadas com uso de diferentes revestimentos, armazenadas a $4 \pm 1^{\circ} \mathrm{C}$, por 12 dias.

\begin{tabular}{cccccccc}
\hline \multirow{2}{*}{ Tratamento } & \multicolumn{7}{c}{ Tempo de armazenamento (dia) } \\
\cline { 2 - 7 } & 0 & 1 & 5 & 7 & 9 & 12 \\
\hline T1 & $5,57^{\mathrm{a}, \mathrm{B}}$ & $5,57^{\mathrm{a}, \mathrm{B}}$ & $5,93^{\mathrm{a}, \mathrm{A}}$ & $5,28^{\mathrm{a}, \mathrm{C}}$ & $4,82^{\mathrm{a}, \mathrm{D}}$ & $4,31^{\mathrm{a}, \mathrm{E}}$ & $3,97^{\mathrm{a}, \mathrm{F}}$ \\
T2 & $5,54^{\mathrm{a}, \mathrm{A}}$ & $5,54^{\mathrm{a}, \mathrm{A}}$ & $5,56^{\mathrm{b}, \mathrm{A}}$ & $5,23^{\mathrm{a}, \mathrm{B}}$ & $4,64^{\mathrm{a}, \mathrm{C}}$ & $4,35^{\mathrm{a}, \mathrm{D}}$ & $4,13^{\mathrm{a}, \mathrm{E}}$ \\
T3 & $5,55^{\mathrm{a}, \mathrm{A}}$ & $5,55^{\mathrm{a}, \mathrm{A}}$ & $5,62^{\mathrm{b}, \mathrm{A}}$ & $5,04^{\mathrm{a}, \mathrm{B}}$ & $4,85^{\mathrm{a}, \mathrm{B}}$ & $4,39^{\mathrm{a}, \mathrm{C}}$ & $4,22^{\mathrm{a}, \mathrm{C}}$ \\
T4 & $5,64^{\mathrm{a}, \mathrm{A}}$ & $5,64^{\mathrm{a}, \mathrm{A}}$ & $5,57^{\mathrm{b}, \mathrm{A}}$ & $5,2^{\mathrm{a}, \mathrm{B}}$ & $4,65^{\mathrm{a}, \mathrm{C}}$ & $4,46^{\mathrm{a}, \mathrm{C}}$ & $4,12^{\mathrm{a}, \mathrm{D}}$ \\
T5 & $5,47^{\mathrm{a}, \mathrm{A}}$ & $5,47^{\mathrm{a}, \mathrm{A}}$ & $5,43^{\mathrm{b}, \mathrm{A}}$ & $5,26^{\mathrm{a}, \mathrm{A}}$ & $4,81^{\mathrm{a}, \mathrm{B}}$ & $4,50^{\mathrm{a}, \mathrm{C}}$ & $4,18^{\mathrm{a}, \mathrm{D}}$ \\
\hline
\end{tabular}

Médias seguidas de mesma letra minúscula na coluna e maiúscula na linha não diferem entre si, pelo Teste de Tukey ( $\mathrm{P}<0,05)$. (T1) Controle; (T2) glicerol $1 \%$ e goma xantana $0,5 \%$; (T3) glicerol $1 \%$, goma xantana $0,5 \%$ e quitosana $1 \%$; (T4) glicerol $1 \%$, goma xantana $0,5 \%$ e guar $0,25 \%$; (T5) glicerol $1 \%$, goma xantana $0,5 \%$, guar $0,25 \%$ e quitosana $1 \%$.

Fonte: Elaboração dos autores.

Tabela 7. Acidez titulável (g ácido cítrico/100g) das amostras de mamão Formosa minimamente processado, tratadas com uso de diferentes revestimentos, armazenadas a $4 \pm 1^{\circ} \mathrm{C}$, por 12 dias.

\begin{tabular}{cccccccc}
\hline \multirow{2}{*}{ Tratamentos } & \multicolumn{7}{c}{ Tempo de armazenamento (dia) } \\
\cline { 2 - 8 } & 0 & 1 & 3 & 5 & 7 & 9 & 12 \\
\hline T1 & $0,058^{\mathrm{a}, \mathrm{D}}$ & $0,061^{\mathrm{a}, \mathrm{D}}$ & $0,082^{\mathrm{a}, \mathrm{C}}$ & $0,096^{\mathrm{a}, \mathrm{B}}$ & $0,096^{\mathrm{a}, \mathrm{B}}$ & $0,101^{\mathrm{a}, \mathrm{B}}$ & $0,112^{\mathrm{a}, \mathrm{A}}$ \\
T2 & $0,058^{\mathrm{a}, \mathrm{F}}$ & $0,062^{\mathrm{a}, \mathrm{E}}$ & $0,075^{\mathrm{b}, \mathrm{c}, \mathrm{D}}$ & $0,089^{\mathrm{b}, \mathrm{C}}$ & $0,089^{\mathrm{b}, \mathrm{C}}$ & $0,098^{\mathrm{a}, \mathrm{B}}$ & $0,109^{\mathrm{a}, \mathrm{A}}$ \\
T3 & $0,058^{\mathrm{a}, \mathrm{E}}$ & $0,061^{\mathrm{a}, \mathrm{E}}$ & $0,073^{\mathrm{c}, \mathrm{D}}$ & $0,089^{\mathrm{b}, \mathrm{C}}$ & $0,089^{\mathrm{b}, \mathrm{C}}$ & $0,101^{\mathrm{a}, \mathrm{B}}$ & $0,109^{\mathrm{a}, \mathrm{A}}$ \\
T4 & $0,058^{\mathrm{a}, \mathrm{E}}$ & $0,060^{\mathrm{a}, \mathrm{E}}$ & $0,073^{\mathrm{c}, \mathrm{D}}$ & $0,089^{\mathrm{b}, \mathrm{C}}$ & $0,089^{\mathrm{b}, \mathrm{C}}$ & $0,102^{\mathrm{a}, \mathrm{B}}$ & $0,111^{\mathrm{a}, \mathrm{A}}$ \\
T5 & $0,058^{\mathrm{a}, \mathrm{F}}$ & $0,062^{\mathrm{a}, \mathrm{E}}$ & $0,078^{\mathrm{a}, \mathrm{b}, \mathrm{D}}$ & $0,091^{\mathrm{b}, \mathrm{C}}$ & $0,091^{\mathrm{b}, \mathrm{C}}$ & $0,099^{\mathrm{a}, \mathrm{B}}$ & $0,109^{\mathrm{a}, \mathrm{A}}$ \\
\hline
\end{tabular}

Médias seguidas de mesma letra minúscula na coluna e maiúscula na linha não diferem entre si, pelo Teste de Tukey ( $\mathrm{P}<0,05)$. (T1) Controle; (T2) glicerol $1 \%$ e goma xantana $0,5 \%$; (T3) glicerol $1 \%$, goma xantana $0,5 \%$ e quitosana $1 \%$; (T4) glicerol $1 \%$, goma xantana $0,5 \%$ e guar $0,25 \%$; (T5) glicerol $1 \%$, goma xantana $0,5 \%$, guar $0,25 \%$ e quitosana $1 \%$.

Fonte: Elaboração dos autores.

\section{Análise microbiológica}

A Figura 1 mostra as contagens de Psicrófilos no mamão Formosa minimamente processado, armazenamentos por doze dias.

Através dos resultados, pode-se observar que as amostrasrevestidas comos diferentes polissacarídeos apresentaram comportamento similar em relação à contagem de micro-organismos, sendo inferiores as contagens obtidas no tratamento controle. Este valor reduzido no crescimento de Psicrófilos pode ser devido à atuação dos revestimentos, goma xantana, goma guar e/ou quitosana, na superfície dos mamões "Formosa" minimamente processados, pela redução da quantidade de água livre na superfície do produto. 
Figura 1. Psicrófilos em amostras de mamão "Formosa" minimamente processado com uso de diferentes revestimentos.

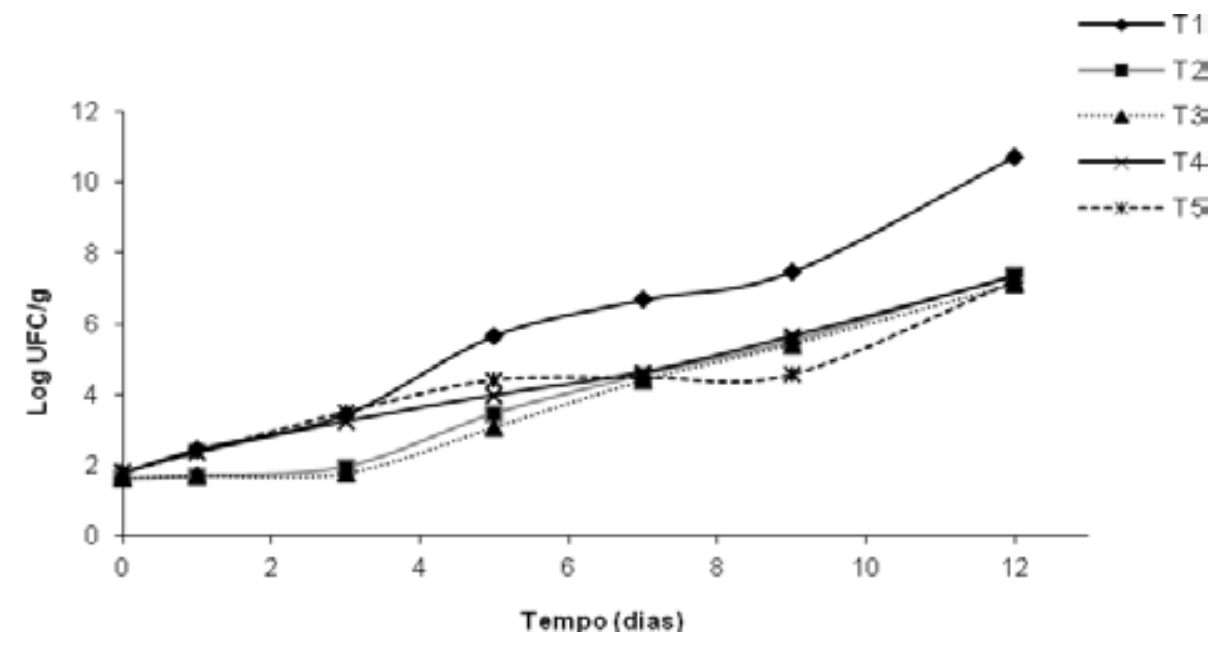

(T1) Controle; (T2) glicerol 1\% e goma xantana 0,5\%; (T3) glicerol 1\%, goma xantana $0,5 \%$ e quitosana $1 \%$; (T4) glicerol $1 \%$, goma xantana $0,5 \%$ e guar $0,25 \%$; (T5) glicerol $1 \%$, goma xantana $0,5 \%$, guar $0,25 \%$ e quitosana $1 \%$.

Fonte: Elaboração dos autores.

Não se observou o efeito antimicrobiano da quitosana indicado por Botrel et al. (2007) e Chien, Sheu e Yang (2007), visto que não houve diferença relevante na contagem dos microorganismos Psicrófilos nos mamões produzidos com os revestimentos dos tratamentos T3 e T5. A inibição destes micro-organismos parece estar mais relacionada à presença do revestimento, independente dos polissacarídeos utilizados. De acordo com Kester e Fennema (1986), o uso de revestimentos de baixa permeabilidade a gases, como é o caso de polissacarídeos, reduz o acesso do oxigênio aos tecidos, minimizando as alterações microbianas.

A presença de coliformes totais e coliformes termotolerantes para todos os tratamentos foi menor que $10^{2} \mathrm{UFC}_{\mathrm{g}} \mathrm{g}^{-1}$, assim como não se detectou a presença de Salmonella nas amostras de mamão "Formosa" minimamente processado, resultados semelhantes foram observados por Sarzi et al. (2002b) e Trigo et al. (2012). Os produtos preparados atenderam o preconizado na legislação, que permite, em frutas frescas preparadas (descascadas ou selecionadas ou fracionadas) sanificadas e refrigeradas, a presença de coliformes termotolerantes em até $5.10^{2}$ UFC.g ${ }^{-1}$ e ausência de Salmonella em $25 \mathrm{~g}$ de amostra (BRASIL, 2001).

\section{Conclusão}

Os diferentes revestimentos à base de goma xantana foram eficientes na conservação do mamão "Formosa" minimamente processado em relação a amostra controle. A adição de goma guar ao revestimento de xantana influenciou negativamente na perda de massa e nos parâmetros de cor, luminosidade, a* e b*. A adição de quitosana (T3) influenciou beneficamente na redução da perda de massa, manutenção da luminosidade e menor redução nos parâmetros a* e b*, entretanto, não foi observado efeito antimicrobiano. Assim, sugerese como revestimento comestível de mamão "Formosa" minimamente processado o revestimento composto somente de goma xantana (T2), o qual propiciou redução da perda de massa, manutenção da luminosidade e $b^{*}$ e menor redução de $a^{*}$. 
Entretanto, experimentos visando à manutenção da firmeza, pH e acidez deverão ser futuramente realizados.

\section{Referências}

AMERICAN PUBLIC HEALTH ASSOCIATION APHA. Compendium of methods for the microbiological examination of foods. Washington, DC, 2001. $676 \mathrm{p}$.

ASSOCIATION OF OFFICIAL ANALYTICAL CHEMISTS - AOAC. Official methods of analysis. $16^{\text {th }}$ ed. Washington: Association of Official Analytical Chemists, 2000.

BEM, M. S. D.; POLESI, L. F.; SARMENTO, S. B. S. Propriedades funcionais de amido de leguminosas em associação à hidrocoloides. Boletim CEPPA, Curitiba, v. 29, n. 1, p. 103-116, 2011.

BESINELA JÚNIOR, E; MONARIM, M. M. S.; CAMARGO, M.; MAHL, C. R. A.; SIMÕES, M. R.; SILVA, C. F. Efeito de diferentes biopolímeros no revestimento de mamão (Carica Papaya $\mathrm{L}$ ) minimamente processado. Varia Scientia Agrárias, Cascavel, v. 1, n. 1, p. 131-142, 2010.

BOTREL, D. A.; SOARES, N. F. F.; GERALDINE, R. M.; PEREIRA, R. M.; FONTES, E, A. F. Qualidade de alho (Allium sativum) minimamente processado envolvido com revestimento comestível antimicrobiano. Ciência e Tecnologia de Alimentos, Campinas, v. 27, n. 1, p. 32-38, 2007.

BRASIL. Agência Nacional de Vigilância Sanitária. RDC $\mathrm{n}^{\circ} 12$ de 2 de janeiro de 2001. Aprova o Regulamento Técnico Sobre Padrões Microbiológicos para Alimentos. Diário Oficial [da] União, Brasília, DF, 10 de jan. 2001. Anexo 1, p. 68.

CAO, N.; FU, Y.; HE, J. Preparation and physical properties of soy protein isolate and gelatin composite films. Food Hydrocolloids, Oxford, v. 21, p. 1153-1162, 2007.

CEREDA, M. P.; BERTOLLINI, A. C.; SILVA, A. P.; OLIVEIRA, M. A.; EVANGELISTA, R. M. Películas de almidón para la preservación de frutas. In: CONGRESSO DE POLÍMEROS BIODEGRADÁBLES, 1995, Buenos Aires. Anais... Buenos Aires: Advances y Perspectivas, 1995. p. 94.

CHIEN, P. J.; SHEU, F.; YANG, F. H. Effects of edible chitosan coating on quality and shelf life of sliced mango fruit. Journal of Food Engineering, Essex, v. 78, n. 1, p. 225-229, 2007.
CHITARRA, M. I. F. Alterações bioquímicas do tecido vegetal com o processamento mínimo. In: SEMINÁRIO SOBRE HORTALIÇAS MINIMAMENTE PROCESSADAS, 1999, Piracicaba. Palestra... Piracicaba: ESALQ-USP, 1999. p. 1-9.

GARCÍA-OCHOA, F.; SANTOS, V. E.; CASAS, J. A.; GÓMEZ, E. Xanthan gum: production, recovery and properties. Biotechnology Advances, United States, v. 18, n. 7, p. 549-579, 2000.

GODOY, R. C. B. de; MATOS, E. L. S.; SANTOS, A. P. dos; LEDO , C. A. da S.; AMORIN, T. da S.; PEREIRA, M. E. C. Avaliação das alterações físico-químicas e químicas de mamão minimamente processado, variedade solo, armazenado em embalagens PET e em bandejas com PVC. In: MARTINS, D. dos S. Papaya Brasil: qualidade do mamão para o mercado interno. Vitória: Incaper, 2003. p. 677-680.

HINOJOSA, R. L.; MONTGOMERY, M. W. Industrialização do mamão. Aspectos bioquímicos e tecnológicos da produção de purê asséptico. In: RUGGIERO, C. Mamão. Jaboticabal: FCAV-UNESP, 1988. p. 89-110.

KESTER, J. J.; FENNEMA, O. R. Edible films and coatings: a review. Food Technology, Chicago, v. 40, n. 12, p. 47-59, 1986.

KROCHTA, J. M.; MULDER-JOHNSTON, C. Edible and biodegradable polymer films: challenges and opportunities. Food Technology, Chicago, v. 51, n. 2, p. 61-74, 1997.

LIMA, A. S.; RAMOS, A. L. D.; MARCELLINI, P. S.; BATISTA, R. A.; FARAONI, A. S. Adição de Agentes antiescurecimento, antimicrobiano e utilização de diferentes filmes plásticos em mamão minimamente processado. Revista Brasileira de Fruticultura, Jaboticabal, v. 27, n. 1, p. 149-152, 2005.

MALI, S.; GROSSMANN, M. V. E.; YAMASHITA, F. Filmes de amido: produção, propriedades e potencial de utilização. Semina Ciências Agrárias, Londrina, v. 31, n. 1, p. 137-156, 2010.

MINOLTA. Precise color communication: color control from feeling to instrumentation. Osaka: Co. Ltda., 1994. $49 \mathrm{p}$.

MORETTI, C. L. Panorama do processamento mínimo de frutas e hortaliças. In: MORETTI, C. L. Manual de processamento mínimo de frutas e hortaliças. Brasília: Embrapa Hortaliças, 2007. cap. 4, p. 25-40. 
OLIVEIRA JÚNIOR, L. F. G.; CARLOS, L. A.; CORDEIRO, C. A. M.; COELHO, E. M.; ARAÚJO, T. M. R. Qualidade de mamão "Golden" minimamente processado armazenado em diferentes temperaturas. Scientia Agraria, Paraná, v. 8, n. 3, p. 219-224, 2007.

PEIXOTO, A. M.; SILVA, S. M.; MARTINS, L. P.; TORRES, L. B. V.; GUIMARÃES, G. H. C. Qualidade de mamão "Golden" minimamente processado e tratado com soluções conservantes. In: CONGRESSO BRASILEIRO DE FRUTICULTURA, 20; TH ANNUAL MEETING OF THE INTERAMERICAN SOCIETY FOR TROPICAL HORTICULTURE, 54., 2008, Vitória. Anais...Vitória: [s.n], 2008.

PEREIRA, M. E. C.; SILVA, A. S.; BISPO, A. S. R.; SANTOS, D. B.; SANTOS, S.B.; SANTOS, V. J. Amadurecimento de mamão Formosa com revestimento comestível à base de fécula de mandioca. Ciência $e$ Agrotecnologia, Lavras, v. 30, n. 6, p. 1116-1119, 2006.

RAO, M. S.; KANATT, S. R.; CHAWLA, S. P.; SHARMA, A. Chitosan and guar gum composite films: Preparation, physical, mechanical and antimicrobial properties. Carbohydrate Polymers, Barking, v. 82, n. 4, p. 1243-1247, 2010.

RIBEIRO, E. P.; SERAVALLI, E. A. G. Química de alimentos. 2. ed. São Paulo: Edgard Blücher, 2007. 184 p.

ROCHA, R. H. C.; NASCIMENTO, S. R. C.; MENEZES, J. B.; NUNES, G. H. S.; SILVA, E. O. Qualidade pós-colheita do mamão Formosa armazenado sob refrigeração. Revista Brasileira de Fruticultura, Jaboticabal, v. 27, n. 3, p. 386-389, 2005.

SARZI，B.; DURIGAN, J. F.; DONADON, J. R.; TEIXEIRA, G. H. A.; LIMA, M. A. Qualidade de produto minimamente processado de mamão 'Formosa' utilizando-se dois tipos de preparo e armazenamento sob diferentes temperaturas. In: CONGRESSO BRASILIERO DE CIÊNCIA E TECNOLOGIA DE ALIMENTOS, 18., 2002, Porto Alegre. Anais... Porto Alegre: [s.n], 2002a. p. 2015-2018.

Armazenamento de produto minimamente processado de mamão 'Formosa' em diferentes embalagens e a $3^{\circ} \mathrm{C}, 6^{\circ} \mathrm{C}$ e $9^{\circ} \mathrm{C}$. In: CONGRESSO BRASILIERO DE FRUTICULTURA, 17., 2002, Belém. Anais... Belém: [s.n], 2002b. CD-ROM.
SILVA, A. V. C.; OLIVEIRA, P. Y.; CARNELOSSI, M. A. G.; MUNIZ, E. N.; NARAIN, N. Temperatura e embalagem para abóbora minimamente processada. Ciência e Tecnologia de Alimentos, Campinas, v. 29, n. 2, p. 391-394, 2009.

SOARES, N. F. F.; GERALDINE, R. M. Embalagens. In: MORETTI, C. L. Manual de processamento mínimo de frutas e hortaliças. Brasília: Embrapa Hortaliças, 2007. cap. 4, p. 153-172.

SOUZA, B. S.; DURIGAN, J. F.; DONADON, J. R.; TEIXEIRA, G. H. A. Conservação de mamão "Formosa" minimamente processado armazenado sob refrigeração. Revista Brasileira de Fruticultura, Jaboticabal, v. 27, n. 2, p. 273-276, 2005.

SOUZA, B. S.; DURIGAN, J. F. Processamento mínimo de mamão. In: MORETTI, C. L. Manual de processamento mínimo de frutas e hortaliças. Brasília: Embrapa Hortaliças, 2007. p. 263-272.

STATSOFT - STATISTICA data analysis software system, version 6.0, StatSoft Inc, Tulsa, OK, USA, 2001.

TAPIA, M. S.; ROJAS-GRAU, M. A.; CARMONA, A.; RODRÍGUEZ, F. J.; SOLIVA- FORTUNY, R.; MARTINBELLOSO, O. Use of alginate- and gellan-based coatings for improving barrier, texture and nutritional properties of fresh-cut papaya. Food Hydrocolloids, Oxford, v. 22, n. 8, p. 1493-1503, 2008.

TEIXEIRA, G. H. A.; DURIGAN, J. F.; MATTUIZ, B. H.; ROSSI JÚNIOR, O. D. Processamento mínimo de mamão "Formosa". Ciência e Tecnologia de Alimentos, Campinas, v. 21, n. 1, p. 47-50, 2001.

TRIGO, J. M.; ALBERTINI, S,; SPOTO. M. H. F.; SARMENTO, S. B. S.; LAI REYES, A. E.; SARRIÉS, G. A. Efeito de revestimentos comestíveis na conservação de mamões minimamente processados. Brazilian Journal of Food Technology, Campinas, v. 15, n. 2, p. 125-133, 2012.

VICENTINO, S. L.; FLORIANO, P. A.; DRAGUNSKI, D. C. Filmes de amidos de mandioca modificados para recobrimento e conservação de uvas. Química Nova, São Paulo, v. 34, n. 8, p. 1309-1314, 2011. 